\title{
Observational Study on the Transitional Boundary Layer
}

\author{
By Junsei Kondo and Shigenori Haginoya \\ Geophysical Institute, Tohoku University, Sendai, 980 Japan \\ (Manuscript received 10 August 1984, in revised form 5 February 1985)
}

\begin{abstract}
Observational study is made on the morning and evening surface boundary layer and on the nocturnal quasi-steady state boundary layer. It is found two type breaking processes of surface inversion layer. For moderate wind cases, a stable surface layer is heated up with nearly uniform heating rate without accompaniment of an unstable layer near the ground surface. For weak wind cases, however, after the unstable layer is formed first near the ground surface, heating process propagates upwards. In these two processes the countergradient heat flux (C.G.H.) is observed. Possible mechanisms of the counter-gradient heat flux are proposed; one is an exchange process between neighboring hot and cold bubbles, the other is the penetration of the hot bubbles into the stable layer.

In quasi-steady night, scaling temperature $\theta_{*}$ is depends on the wind speed and surface cooling rate, and the ratio of sensible heat flux to net radiation is proportional to the surface friction velocity.
\end{abstract}

\section{Introduction}

Similarity theory has formulated and well explained the steady state boundary layer. However the morning and evening boundary layer with a rapid change of stability has not been explained well by the steady state similarity theory. This is caused by the fact that real boundary layers are non stationary. Up to the present, the boundary layer transition has been studied more closely for the whole planetary boundary layer than for the surface boundary layer. Many observations, which were carried out by moving platforms such as balloons and airplaines, revealed transitional boundary layers between some tens of meters and $2 \mathrm{~km}$ (Wangara ex., 1967 (Clark et al., 1971); Minnesota ex., 1973 (Izumi \& Caughey, 1976); Kaimal et al., 1976; Caughey et al., 1979). These observations found that the mixed layer develops in the daytime. On the other hand the evening stable layer develops by some height and remains as nearly constant height during night. In these observations, however, the transitional surface layer has not been well investigated.

The first purpose of the present study is to make an analysis of a set of data, that includes both stable to unstable transition and vice versa. The data were obtained by the observation of the morning and evening surface boundary layer over horizontally uniform flat terrain. The second purpose is to make an analysis on the phenomenon of counter gradient heat transport which appears in the transitional surface layer as well as in the upper half of the mixed layer. From the analysis the mixing length is estimated. The third purpose is to find out the relations among the scaling temperature $\theta_{*}$, the wind velocity, and the cooling rate in the nocturnal quasi-steady state surface layer.

\section{Observation}

\subsection{Site}

The site of the experiment was Kitaura in the Osaki Plain about $35 \mathrm{~km}$ north of Sendai, Japan. The section is located in a paddy area whose fetch is about $10 \mathrm{~km}$ in the 
prevailing wind direction in winter (Kondo et al., 1978). Observation were made over 4 period, December 1978, March 1979, March 1980 and April 1981. During the observations the area was covered with stubble whose height was about $10 \mathrm{~cm}$ above the non saturated bare soil surface.

\subsection{Instruments and data analysis}

The mean wind profile was obtained by three-cup anemometers (Kondo \& Sato, 1982). The mean temperature profile was measured by thermistor thermometers which were set into a double ventilation tube to be shaded from the sun. The ventilation velocity was 4 meter per second. The instruments were mounted at heights of $10 \mathrm{~m}, 6 \mathrm{~m}, 3 \mathrm{~m}, 1.5 \mathrm{~m}$, $0.75 \mathrm{~m}$, and $0.3 \mathrm{~m}$. Surface temperature $\left(T_{S}\right)$ and soil temperatures were obtained by platinum wire resistance thermometers. Solar radiation $\left(S^{\downarrow}\right)$ was measured by a whole sky pyranometer (EKO Ltd., Japan). Downward long wave radiation $\left(L^{\downarrow}\right)$ was measured by a pyradiometer (EKO Ltd., Japan). Net radiation $(R n)$ is given by

$$
R n=(1-\gamma) S^{\downarrow}+\varepsilon\left(L^{\star}-\sigma T_{S}^{4}\right)
$$

where

$\gamma$ : surface albedo $(=0.21$ was obtained by the present observations.)

$\varepsilon:$ surface emissivity ( $=0.95$ was assumed)

$\sigma$ : Stefan-Boltzmann constant $\left(=8.132 \times 10^{-11} \mathrm{cal} \cdot \mathrm{cm}^{-2} \cdot \mathrm{K}^{-4}\right)$.

Momentum flux $\rho \overline{u w}$ and sensible heat flux $C_{p} \rho \overline{\theta w}$ were observed by eddy correlation method. Fluctuating wind components were measured with sonic anemometers (Kaijo Denki, Model PA112-1 and PAT311-1). The temperature fluctuations were obtained with $0.1 \mathrm{~mm}$ diameter copper-constantan thermocouple thermometers (1978, 1979, 1980 periods) or with $10 \mu \mathrm{m}$ diameter helix-tungsten-wire resistance thermometers (1981 period). The response times of these thermometers were 0.2-0.3 seconds. In order to prevent solar radiational heating, the thermometer element was shaded with a cover (1978-1980 periods) or it was set into a tube with ventilation air speed of 1 meter per second (1981 period).
The momentum flux was measured at a height of $9 \mathrm{~m}$. The sensible heat fluxes were obtained at 2 levels ( $9 \mathrm{~m}$ and $4 \mathrm{~m}$ heights) for 23 series and at 3 levels $(9 \mathrm{~m}, 7 \mathrm{~m}$, and $4 \mathrm{~m}$ heights or $9 \mathrm{~m}, 4 \mathrm{~m}$, and $1 \mathrm{~m}$ heights) for 13 series.

Mean values were sampled by a data gathering set (Chino Procos VII) every minute. Fluctuation values of wind speed and air temperature were recorded by an analog data recorder and were sampled 10 or 12.5 times per second. In order to eliminate trends, averaging periods used were 1 minute and 10 minutes.

A run length was 10 minutes. In all, 596 runs have been analysed. A series is composed of 10-20 runs which consist of a continuous observation of $2-3$ hours. In all, 36 series were obtained.

\subsection{Nctation}

Parameters used in this paper are defined as follows :

$$
\begin{aligned}
H_{z}=C_{p} \rho(\bar{\theta} \bar{w})_{z}: & \text { momentum flux } \\
& \text { sensible heat flux at a } \\
& \text { estimated from the eddy } \\
& \text { correlation method }
\end{aligned}
$$

$H_{0}$ : sensible heat flux at the surface estimated from the mean air- and windprofiles

$$
u_{*}=\sqrt{-u w}: \text { friction velocity }
$$

$$
\theta_{*}=-\frac{1}{u_{*}} \cdot \frac{H_{0}}{C_{p} \rho}: \text { scaling temperature }
$$

$$
\begin{gathered}
R i=\frac{g}{\Theta} \cdot \frac{\frac{\partial \Theta}{\partial z}}{\left(\frac{\partial U}{\partial z}\right)^{2}}: \text { Richardson number } \\
R f=\frac{g}{\Theta} \cdot \frac{\frac{\partial w}{\theta w}}{\overline{u w}-\frac{\partial U}{\partial z}}: \text { flux Richardson number } \\
L=\frac{u_{*}^{2}}{k \frac{g}{\Theta} \theta_{*}}: \text { Monin-Obukhov stability } \\
\text { length } \\
\zeta=\frac{z}{L}: \text { a dimensionless height } \\
\alpha(\zeta)=\frac{K_{H}}{K_{M}}: \text { ratio of the eddy diffusiv- } \\
\text { ities }
\end{gathered}
$$


$\varphi(\zeta)=\frac{k z}{u_{*}} \cdot \frac{\partial U}{\partial z}: \underset{\text { shear }}{\text { a dimensionless wind }}$

$\varphi_{h}(\zeta)=\frac{k z}{\theta_{*}} \cdot \frac{\partial \Theta}{\partial z}:$ a dimensionless temperawhere

$u, w$ : longitudinal and vertical components of the fluctuation wind

$\theta$ : potential temperature fluctuation

$U_{z}$ : mean horizontal wind at a height of $z$ (in meter)

$\Theta_{z}$ : mean potential temperature at a height of $z$ (in meter)

$\sigma_{\theta}:$ standard deviation of temperature fluctuation

$\sigma_{w}$ : standard deviation of vertical wind fluctuation

$K_{M}$ : eddy diffusivity for momentum

$K_{H}$ : eddy diffusivity for heat

$k$ : von Kármán constant

$g:$ gravitational acceleration

$\rho:$ air density

$C_{p}$ : specific heat of air at constant pressure the over bar "_" denotes time average.

Under the conditions of $U_{10}<3 \mathrm{~m} \cdot \mathrm{s}^{-1}$, wind speed is possible to decrease at the level below which cup anemometer cannot be response and velocity gradient cannot be measured with a high accuracy, so that $R i$ and $R f$ were used for $U_{10} \geqq 3 \mathrm{~m} \cdot \mathrm{s}^{-1}$.

From the definitions, the following relations are obtained:

$$
\begin{aligned}
& R f=\alpha(\zeta) R i=\frac{\zeta}{\varphi(\zeta)} \\
& R i=\frac{\zeta}{\varphi(\zeta)} \cdot \frac{1}{\alpha(\zeta)} \\
& \frac{\overline{\theta w}}{k u_{*} z}=-\frac{1}{\varphi_{h}(\zeta)} \cdot \frac{\partial \Theta}{\partial z}
\end{aligned}
$$

\section{Results and discussion}

\subsection{Heat flux divergence and heating rate}

With the mean wind direction as $x$-axis, the temperature field is assumed homogeneous in the $y$-direction. The rate of change of the mean potential temperature is written as

$$
\frac{\partial \Theta}{\partial t}=-\frac{\partial \overline{\theta w}}{\partial z}-U \frac{\partial \Theta}{\partial x}-\frac{1}{C_{p} \rho} \cdot \frac{\partial R n}{\partial z}
$$

where the first term of the right hand side is the heating rate by heat flux divergence, the second term is the advective heating rate and the third term is the radiational heating rate. Upon integration with respect to $z$, Eq. (5) becomes

$$
(\overline{\theta v})_{z}=\left(\frac{H_{z}}{C_{p} \rho}\right)_{\mathrm{cal}}+A D V+R A D
$$

where

$$
\begin{aligned}
& \left(\frac{H_{z}}{C_{p} \rho}\right)_{\mathrm{cal}}=-\int_{0}^{z} \frac{\partial \Theta}{\partial t} d z+\frac{H_{0}}{C_{p} \rho} \\
& A D V=-\int_{0}^{z} U \frac{\partial \Theta}{\partial x} d z \\
& R A D=-\frac{1}{C_{p} \rho}\left(R n_{z}-R n_{0}\right) .
\end{aligned}
$$

The upward heat flux at the surface, $H_{0}$, can be estimated by the logarithmic temperature profile near the surface,

$$
\begin{aligned}
\frac{H_{0}}{C_{p} \rho} & =\left(K_{H} \frac{\partial \Theta}{\partial z}\right)_{0}=-\left(k^{2} z^{2} \frac{\partial U}{\partial z} \cdot \frac{\partial \Theta}{\partial z}\right)_{0} \\
& =-k^{2}\left(\frac{\partial U}{\partial \ln z}\right)_{0}\left(\frac{\partial \Theta}{\partial \ln z}\right)_{0}
\end{aligned}
$$

Although momentum flux is approximately constant, sensible heat flux does not constant within the transitional surface layer.

The advection term is evaluated by

$$
A D V \doteqdot-U_{3}\left(\frac{\partial \Theta}{\partial x}\right)_{3} z
$$

where $(\partial \Theta / \partial x)_{3}$ is the horizontal temperature gradient at a height of $3 \mathrm{~m}$.

The advective heating term was observed for 3 series of 36 series in all. The horizontal temperature gradient $(\partial \Theta / \partial x)_{3}$ was obtained from the temperature measurements at $z=3 \mathrm{~m}$ at the up- and down-wind sites which are $500 \mathrm{~m}$ from the main tower. The magnitude of the advection term was estimated at about $\pm 0.1^{\circ} \mathrm{C} \cdot \mathrm{cm} \cdot \mathrm{s}^{-1}$.

The radiational heating term was estimated through Yamamoto's Radiation Chart (Yamamoto, 1952) at

$$
R A D \doteqdot 0.1^{\circ} \mathrm{C} \cdot \mathrm{cm} \cdot \mathrm{s}^{-1} .
$$

Fig. 1 is a comparison between $(\overline{\theta w})_{z}$ and $\left(H_{z} / C_{p} \rho\right)_{\text {cal }}$ at $z=9 \mathrm{~m}$. The averaging period for Fig. 1(a) is 10 minutes and that for Fig. 


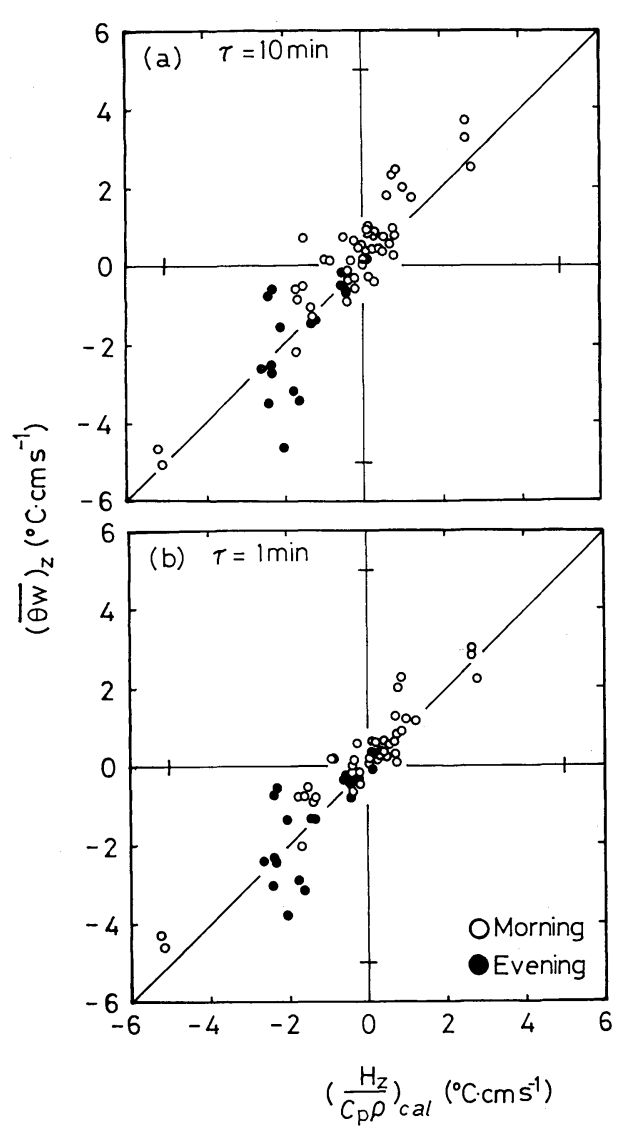

Fig. 1 Observed heat flux $(\overline{\theta w})_{z}$ versus calculated heat flux $\left(H_{z} / C_{p} \rho\right)_{\text {cal }}$. Observing time are 1-3 hours. (a) Averaging time $\tau$ is $10 \mathrm{~min}$ utes, (b) $\tau=1$ minute.

1 (b) is 1 minute. Each point is an average over each series. There is no remarkable difference is seen between both figures. Although some scatter is seen in the plotted points, on the average, $(\bar{\theta} \bar{w})_{z}$ is found to be roughly equal to $\left(H_{z} / C_{p} \rho\right)_{\text {cal }}$.

\subsection{Two heating patterns after sunrise}

Fig. 2 represents the successive 10-min profiles of the mean potential temperature: (a) for a moderate wind case $\left(u_{*}=25.5 \mathrm{~cm} \cdot \mathrm{s}^{-1}\right.$, $U_{10}=6.11 \mathrm{~m} \cdot \mathrm{s}^{-1}$ ) and (b) for a weak wind case $\left(u_{*}=4.7 \mathrm{~cm} \cdot \mathrm{s}^{-1}, U_{10}=1.16 \mathrm{~m} \cdot \mathrm{s}^{-1}\right)$. Fig. 3 shows the corresponding time changes of heat flux at each height.

For the moderate wind case, the following features can be seen; just after sunrise the net radiation loss from the ground surface
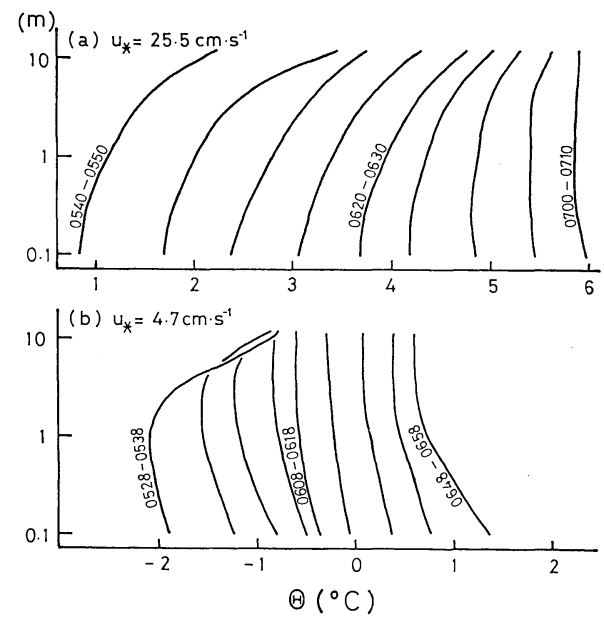

Fig. 2 Example of time variation of potential temperature profile. (a) $u_{*}=25.5 \mathrm{~cm} \cdot \mathrm{s}^{-1}$, (b) $u_{*}=4.7 \mathrm{~cm} \cdot \mathrm{s}^{-1}$.
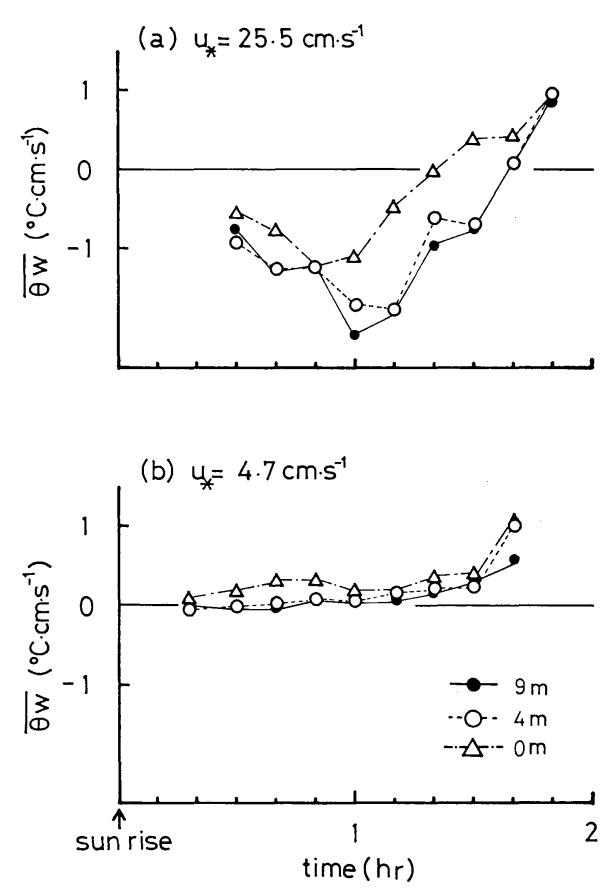

Fig. 3 Example of time variation of heat flux $\overline{\theta w}$. (a) Observing period is as same as (a) of Fig. 2. (b) Observing period is as same as (b) of Fig. 2.

decreases and the surface cooling begins to cease, hence the whole air layer with stable stratification is heated by downward heat flux from the higher layer at a nearly constant heating rate and without the development of an unstable layer near the ground. In this 
case, the stable state continued for 70 minutes from sunrise.

For the weak wind case, an unstable layer arises near the surface about 20 minutes after sunrise, while cooling continues in the higher layers. In this case, the surface layer is heated up gradually by upward heat flux which is supplied from the ground surface already warmed up with sunshine.

Except for few cases of the present observation, the heating pattern is similar to that of Fig. 2(a) for the range $u_{*} \geqq 10 \mathrm{~cm} \cdot \mathrm{s}^{-1}$ $\left(U_{10} \geqq 2 \mathrm{~m} \cdot \mathrm{s}^{-1}\right)$, and to that of Fig. 2(b) for the range $u_{*}<10 \mathrm{~cm} \cdot \mathrm{s}^{-1}\left(U_{10}<2 \mathrm{~m} \cdot \mathrm{s}^{-1}\right)$.

Fig. 4 shows the difference between heating rate at $z=0.3 \mathrm{~m}$ and that at $z=10 \mathrm{~m}$, $(\partial \Theta / \partial t)_{0.3}-(\partial \Theta / \partial t)_{10}$, plotted against $u_{*}$ for conditions of $H_{9}<0$ and $H_{0}>0$. The plotted points are distinguished according to the time elapsed since the surface heating has started, but they do not display any special features.

From the analysis it is found that the heating pattern of the surface layer depends on $u_{*}$ (and $U$ ) and not on the time elapsed since the surface heating has started.

\subsection{Counter gradient heat flux}

The relationship between the Richardson number and the flux Richardson number $(R i$ vs. $R f$ ) in the steady state has been examined in previous studies (Businger et al., 1971; Kondo et al., 1978; Wieringa, 1980). In this section $R i$ vs. $R f$ is examined in the transitional state for $U_{10} \geqq 3 \mathrm{~m} \cdot \mathrm{s}^{-1}$. The data are classified into two cases: (i) the case of a monotonic temperature profile with positive or negative gradient below $z=9 \mathrm{~m}$ ("Monotonic profile"), (ii) the case of a bottom shallow unstable layer capped by an upper deep stable layer ("Stable above the unstable profile"). Note that even though the temperature in early morning shows "Monotonic profile" with positive gradient (stable), it becomes "Stable above the unstable profile" in late morning. Fig. 5 and Fig. 6 show the relation between $R i$ vs. $R f$ for cases (i) and (ii), respectively.

In Fig. 5 some previous studies (Kondo et al., 1978; Wieringa, 1980) are shown for comparison. It is found that the ratio $\alpha(\zeta)=$ $R f / R i$ (Eq. (2)) is smaller than 1 in stable

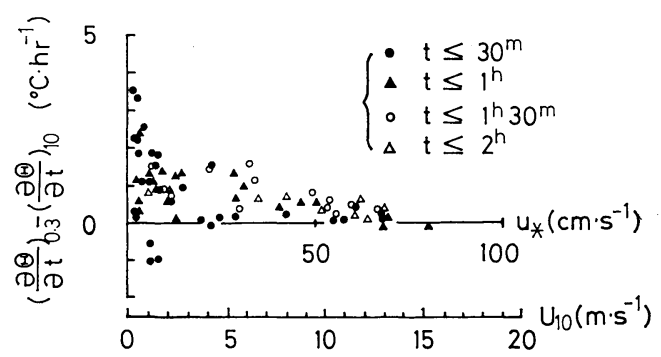

Fig. 4 Relation between the difference of the heating rate at a height of 0.3 meter and that at 10 meter and the friction velocity. The data satisfy the following conditions; the surface heating rate is positive and the direction of heat flux at $z=9 \mathrm{~m}$ is downward. The wind speed at $z=10 \mathrm{~m}$ is calculated for neutral conditions with a surface roughness length of $z_{0}=0.5 \mathrm{~cm}$.

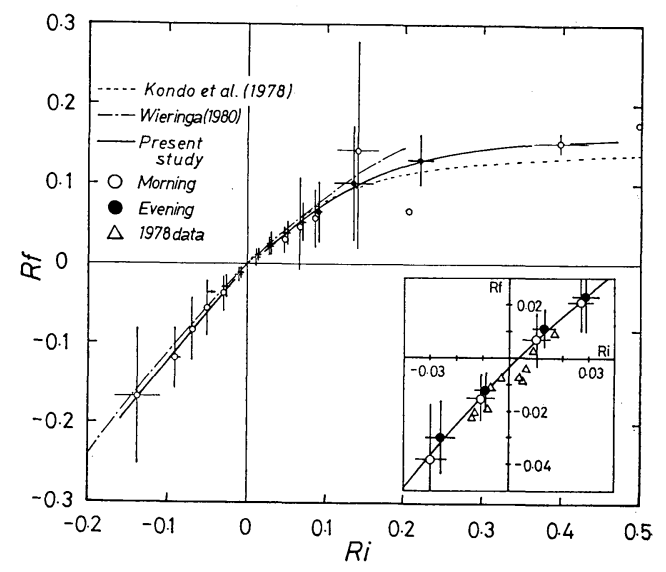

Fig. 5 Relation between the gradient Richardson number ( $\mathrm{Ri}$ ) and the flux Richardson number (Rf) for "Monotonic profile" case.

cases, and greater than 1 in unstable cases. These results agree with the previous studies. A magnification figure near the origin is shown in the inset figure. It is seen that the solid line does not pass through the origin but through the point $(0.003,0)$, that is

$$
\overline{\theta w}>0 \text { at } 0.003>R i \geqq 0 .
$$

This implies the occurrence of a countergradient heat flux in the slightly stable layer.

Fig. 6 is for "Stable above the unstable layer" case. in which the solid line is the same solid line as Fig. 5 . In this case, $R f=0$ at $R i=0.02$ and the counter-gradient heat flux becomes even stronger, that is 


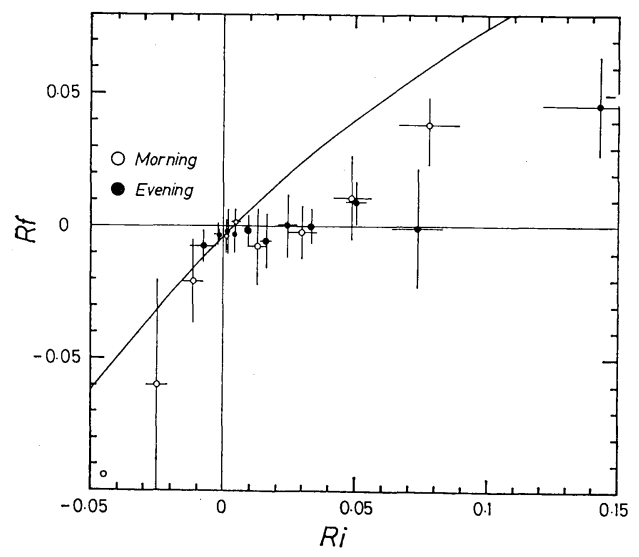

Fig. 6 Same as Fig. 5 except for "Stable above the unstable profile" case.

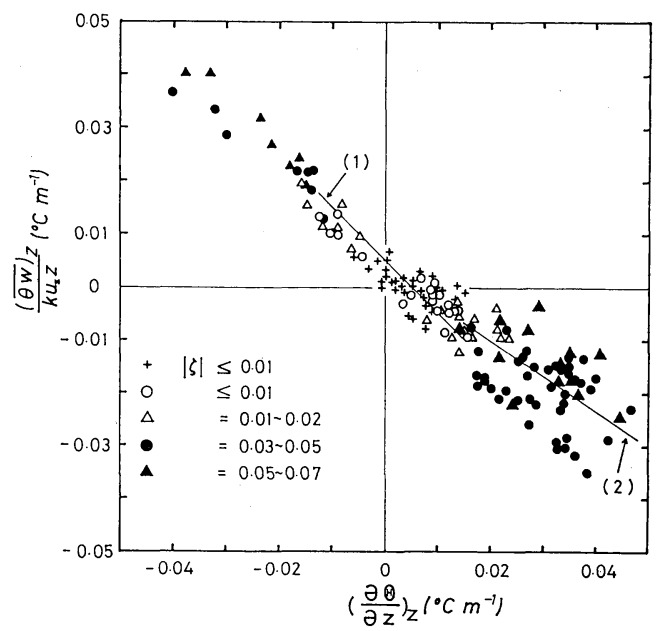

Fig. 7 Relation between the potential temperature gradient $(\partial \Theta / \partial z)$ and the heat flux divided by $k u_{*} z$. Solid line $(1)$ is $\varphi_{h}(\zeta)=1$, line (2) is $\varphi_{h}(\zeta)=1+10 \zeta$, where $\zeta=0.05$.

$$
\overline{\theta w}>0 \text { at } 0.02>R i \geqq 0 .
$$

Fig. 7 shows the above results more definitely. This figure indicates the relation between the potential temperature gradient $\partial \Theta / \partial z$ and the heat flux divided by $k u_{*} z$. The plotted points are distinguished by the range of $|\zeta|$. It is obtained from this figure that

$$
\begin{aligned}
& \overline{\theta w}>0 \text { for }\left(\frac{\partial \Theta}{\partial z}\right)_{\bar{\theta} \bar{w}=0}>\left(\frac{\partial \Theta}{\partial z}\right)>0 \\
& \overline{\theta w}=0 \text { for }\left(\frac{\partial \Theta}{\partial z}\right)=\left(\frac{\partial \Theta}{\partial z}\right)_{\overline{\theta w}=0}
\end{aligned}
$$

$$
\overline{\theta w}<0 \text { for }\left(\frac{\partial \Theta}{\partial z}\right)>\left(\begin{array}{c}
\partial \Theta \\
\partial z
\end{array}\right)_{\bar{\theta} \bar{w}=0}
$$

where $(\partial \Theta / \partial z) \overline{\theta w}=0$ means the potential temperature gradient at $\overline{\theta w}=0$ which is found from the present observation as

$$
\left(\frac{\partial \Theta}{\partial z}\right)_{\overline{\theta w}=0}=0.005^{\circ} \mathrm{C} \cdot \mathrm{m}^{-1}\left(=5^{\circ} \mathrm{C} \cdot \mathrm{km}^{-1}\right),
$$

and

$$
\varphi_{h}(\zeta)=1, \text { for }|\zeta| \leqq 0.02 .
$$

With reference to Eq. (4), (13) and (14) one can find

$$
\frac{\overline{\theta w}}{k u_{*} z}=-\frac{1}{\varphi_{h}(\zeta)}\left\{\left(\frac{\partial \Theta}{\partial z}\right)-\left(\frac{\partial \Theta}{\partial z}\right)_{\theta \bar{w}=0}\right\}
$$

Eq. (15) is useful for practical purposes. This empirical formulation was proposed by Deardorff (1966) first, but his value of $(\partial \Theta / \partial z)_{\overline{\theta w}=0}$ was $0.65^{\circ} \mathrm{C} \cdot \mathrm{km}^{-1}$ for mixed layer. The solid line (2) in Fig. 7 is given by

$$
\begin{aligned}
& \varphi_{h}(\zeta)=1+C \zeta \\
& C=10
\end{aligned}
$$

It is well known from previous studies (e.g. Yaglom, 1977) that $C$ ranges from 4.1 to 13.6 under stable conditions.

\subsection{Proposed mechanisms of C.G.H.}

The following two mechanisms are considered when upward heat flux is observed for a positive potential temperature gradient.

(a) exchanging of adjacent hot and cold thermals

(b) hot thermal penetrations into the stable layer

To explain mechanism (a) and (b), mixing length theory is introduced here. Fig. 8 shows the model of mechanism (a). The thick solid line shows the mean potential temperature profile whose vertical gradient is $(\partial \Theta / \partial z)$ and the horizontal bar shows the product of the standard deviation of temperature fluctuations $\sigma_{\theta}$ and a constant $\beta$. The broken line shows the departure $l$ of an air parcel, and the arrow indicates the direction of its motion. The left part of the figure shows the condi- 


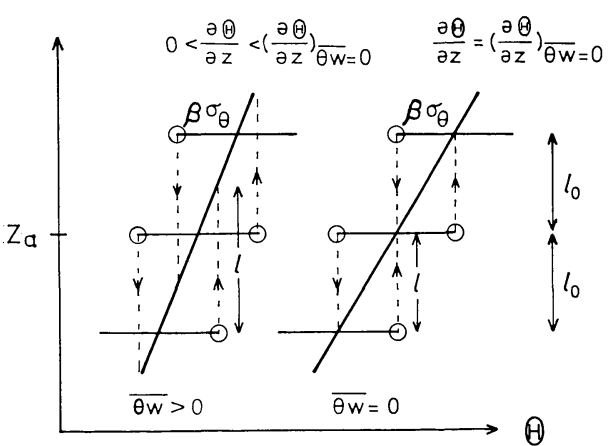

Fig. 8 Model sketch of C. G. H. mechanism.

tion $\overline{\theta w}>0$ with

$$
\left(\frac{\partial \Theta}{\partial z}\right)_{\overline{\theta w}=0}>\left(\frac{\partial \Theta}{\partial z}\right)>0 \text {. }
$$

The right part shows the condition $\overline{\theta w}=0$ with

$$
\left(\frac{\partial \Theta}{\partial z}\right)=\left(\frac{\partial \Theta}{\partial z}\right)_{\overline{\theta w}=0} .
$$

When

$$
\left(\frac{\partial \Theta}{\partial z}\right)>\left(\frac{\partial \Theta}{\partial z}\right)_{\overline{\theta w}=0}
$$

(not shown) it appears $\overline{\theta w}<0$. C.G.H. is observed when a hot bubble $(\theta>0)$ with upward flow $(w>0)$ has a departure " $l$ " or when cold bubble $(\theta<0)$ with downward flow $(w<0)$ has departure " $l$ ", provided that " $l$ " is greater than the mixing length " $l_{0}$ ". Under these conditions upward heat transport by buoyancy occurs. This can be formulated as follows.

It is assumed that

$$
\sigma_{\theta} \propto l\left(\frac{\partial \Theta}{\partial z}\right)
$$

so that the condition of C.G.H. occurrence is

$$
l>l_{0}=\beta \sigma_{\theta}(\overline{\theta w}=0)\left(\frac{\partial \Theta}{\partial z}\right)_{\overline{\theta w}=0}^{-1}
$$

where $\sigma_{\theta}(\overline{\theta w}=0)$ denotes the temperature fluctuation for $\overline{\theta w}=0$, The value of $\beta$ is a constant, which is determined next. According to Fig. 14 (shown below), it is found that

$$
\sigma_{\theta}(\overline{\theta w}=0)=0.08^{\circ} \mathrm{C}
$$

The mixing length of the surface layer at $z=9 \mathrm{~m}$ for near neutral conditions is

$$
l_{0}=k z \doteqdot 3.6 \mathrm{~m} \text {. }
$$

Thus $\beta=0.23$ is obtained by substituting Eq. (13), (19) and (20) into (18). This value is used in the discussion below. The heat transport of the "Stable monotonic profile" condition with no heated unstable layer near the ground can be explained by this mechanism.

C. G. H. by mechanism (b) is observed when a hot bubble generated just above the heated surface penetrate into the upper stable layer. This mechanism explains the heat transport of "Stable above the unstable profile" condition. The mixing length $l_{0}$ can be obtained by using the above value of $\beta$. At $z=9 \mathrm{~m}$ (see Fig. 14)

$$
\begin{aligned}
& \sigma_{\theta}(\overline{\theta w}=0)=0.06^{\circ} \mathrm{C} \\
& \left(\frac{\partial \Theta}{\partial z}\right)_{\overline{\theta w}=0}=0.005^{\circ} \mathrm{C} \cdot \mathrm{m}^{-1} .
\end{aligned}
$$

Substitute these values into Eq. (18), to obtain $l_{0}=2.8 \mathrm{~m}$.

This value is smaller than $3.6 \mathrm{~m}$ in the "Monotonic profile".

Next, we extend the above considerations to the upper part of the mixed layer for the purpose of obtaining the mixing length of the mixed layer. Fig. 9 displays the observational data from other researchers. The letters indicating the profiles in this figure correspond to those in the note in Table 1. Except for (e), the left half of each figure shows the potential temperature profile (thick solid line) and temperature fluctuations (horizontal bar), and the right half shows the heat flux profile. The "triangle mark" indicated on the temperature profile is the height where the heat flux is zero $z_{\overline{\theta w}=0}$. These features in the unstable mixed layer are similar to "Stable above the unstable profile" in the transitional surface layer. So the mixing length in the upper part of the mixed layer can be obtained through the same analysis as shown above.

Mixing lengths $l_{0}$ were obtained by Eq. (18). This value is regarded as the value at the height where $\overline{\theta w}=0$ in the stable layer, 

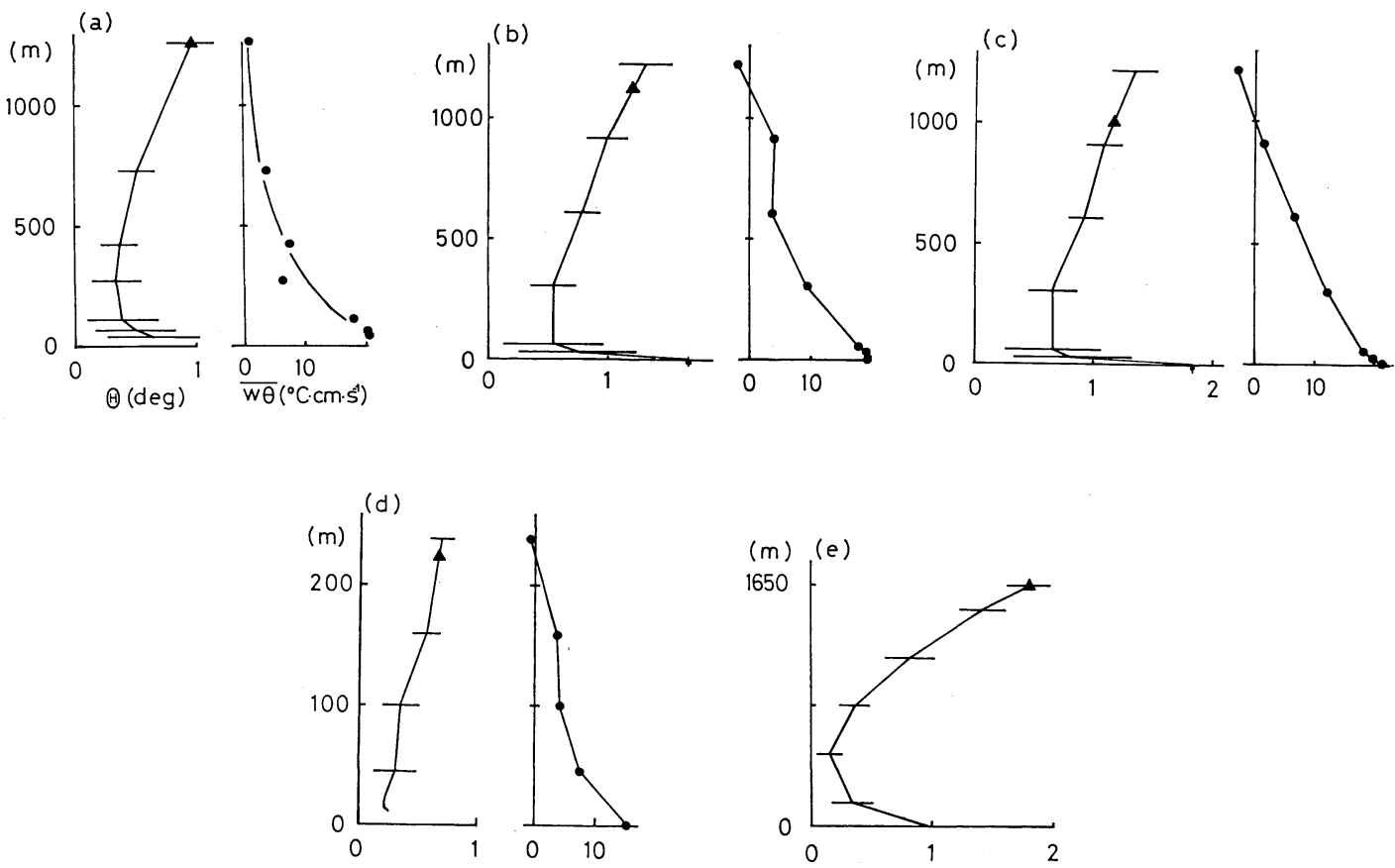

Fig. 9 Potential temperature profile and heat flux profile obtained from various C. G. H. observations. As for the figure number (a), (b), $\cdots$, see Table 1. (e) shows only the virtual potential temperature profile. In the figure, horizontal bar indicates the magnitude of $\sigma_{\theta}$, a closed triangle indicates the height of zero heat flux.

in the top part of the planetary boundary layer.

These results are summarized in Table 1. The following are shown in the table; the height where the heat flux is zero: $z_{\overline{\theta w}=0}$, temperature fluctuation: $\sigma_{\theta}(\overline{\theta w}=0)$ at that height, potential temperature gradient: $(\partial \Theta / \partial z)_{\overline{\theta w}=0}$, mixing length : $l_{0}$, the height of the minimum potential temperature (unstable layer height): $h_{1}$, the depth of C.G.H. layer : $\Delta h\left(=z_{\overline{\theta w}=0}-h_{1}\right)$, potential temperature difference between the surface $z_{a}$ (about $10 \mathrm{~m}$ ) and a height of $h_{1}:\left(\Theta_{a}-\Theta_{h_{1}}\right)$, and surface heat flux: $H_{0} / C_{p} \rho$. The upper half of Table 1 shows the results of mixed layer observations. The lower half of the table shows the results of surface layer observations. The following becomes clear from the table.

$$
\frac{l_{0}}{\overline{z_{\overline{\theta w}}}=0}=0.042 \text { (average) }
$$

in the mixed layer, whereas

$$
\frac{l_{0}}{z_{\overline{\theta w}=0}}=0.31-0.4 \leqq k
$$

in the surface layer.

(Note) In the present study we have made use of the potential temperature $\Theta$ instead of the virtual potential temperature $\Theta_{V}$. The difference between $(\partial \Theta / \partial z)$ and $\left(\partial \Theta_{V} / \partial z\right)$ is small as

$$
\left(\frac{\partial \Theta}{\partial z}\right)-\left(\frac{\partial \Theta_{V}}{\partial z}\right)\left\{\begin{aligned}
\doteqdot & 0.0009^{\circ} \mathrm{C} \cdot \mathrm{m}^{-1} \\
& \text { for surface layer } \\
\doteqdot & 0.0003^{\circ} \mathrm{C} \cdot \mathrm{m}^{-1} \\
& \text { for mixed layer }
\end{aligned}\right.
$$

so that the present results do not change remarkably, even if $\Theta_{V}$ is used in the analysis.

\subsection{Morning transition}

Fig. 10 shows an example of the time variation of physical quantities during the morning transitional processes. $k(\partial \Theta / \partial \ln z)_{0}$ and $k(\partial \Theta / \partial \ln z)_{9}$ are the measures of the mean potential temperature gradient at the 


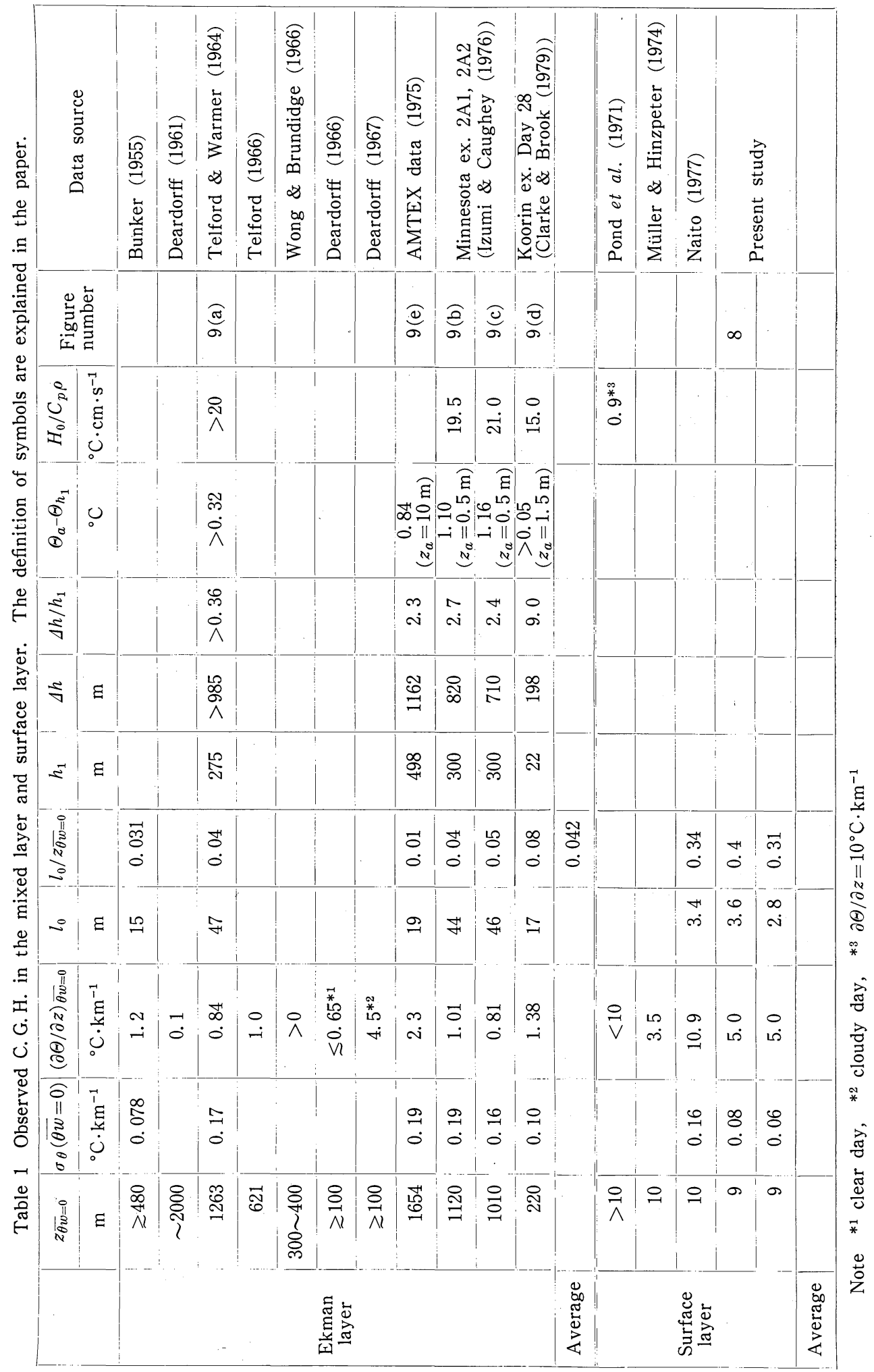


surface and at a height of $9 \mathrm{~m}$, respectively. The surface heat flux $H_{0}$ was obtained by Eq. (10), so that the sign of $k(\partial \Theta / \partial \ln z)_{0}$ and $H_{0}$ change simultaneously. The sign of $S^{\downarrow}$ and $R n$ are positive when energy flows toward the surface. In the morning net radiation $R n$ changes sign from minus to plus, and next the heat flux changes sign from minus to plus too. The time intervals between sunrise and the change in sign of the heat flux at $z=0 \mathrm{~m}, t\left[H_{0}\right]$, and that at $z=9 \mathrm{~m}$, $t\left[H_{9}\right]$, are 74 minutes and 104 minutes, respectively. The time intervals between sunrise and the change in sign of the potential temperature gradient, $t\left[-(\partial \Theta / \partial z)_{9}\right]$, is 118 minutes. The minimum value in $\sigma_{\theta}(z=9 \mathrm{~m})$ appears when $H_{9}=0$. The value of $\sigma_{w}(z=$ $9 \mathrm{~m}$ ) begin to increase gradually after sunrise.

Table 2(a) shows the average time intervals between sunrise and when the physical quantities change sign. The upper half is a 6 series average, for moderate wind cases. Lower half is a 9 series average, for weak wind cases. The time intervals $t\left[H_{9}\right]-t\left[H_{0}\right]$ which are considered the break-up times of the surface inversion layer from $z=0 \mathrm{~m}$ to $z=9 \mathrm{~m}$ obtained by heat flux, range from 12 to 16 minutes. The time intervals $t\left[-(\partial \Theta / \partial z)_{9}\right]$ $-t\left[H_{0}\right]$ which are considered the break-up times of the surface inversion layer from $z=0 \mathrm{~m}$ to $z=9 \mathrm{~m}$ obtained by the potential temperature profiles, are 40 minutes. The time intervals $t\left[-(\partial \Theta / \partial z)_{9}\right]-t\left[H_{9}\right]$ which are considered duration times of C.G.H., are 22 minutes. In summary, the average morning transitions after sunrise occur in the following sequence; $S^{\downarrow}=0, R n=0, H_{0}=0, H_{9}=0$ and $(\partial \Theta / \partial z)_{9}=0$.
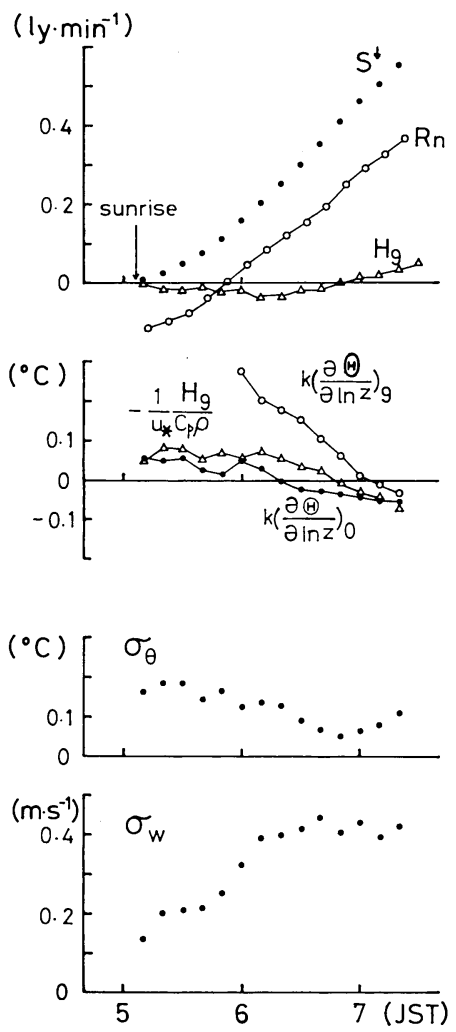

Fig. 10 Example of time variation for solar radiation $\left(S^{\downarrow}\right)$, net radiation $(R n)$, heat flux at $z=9 \mathrm{~m}\left(H_{9}\right)$, a measure of the potential temperature gradient at the surface and that at $z=9 \mathrm{~m}\left(k(\partial \Theta / \partial \ln z)_{0}, k(\partial \Theta / \partial \ln z)_{9}\right)$, and intensity of turbulent fluctuations $\left(\sigma_{\theta}, \sigma_{w}\right)$, for morning transition. $1 \mathrm{ly} \cdot \mathrm{min}^{-1}$ is equivalent to $53.7^{\circ} \mathrm{C} \cdot \mathrm{cm} \cdot \mathrm{s}^{-1}$.

Table 2 Average time interval of the physical quantity change sign. The definition of symbols are explained in the paper. Data are obtained in early spring.

\begin{tabular}{|c|c|c|c|c|c|c|}
\hline (a) & $\begin{array}{l}\text { sunrise } \\
\text { JST }\end{array}$ & $\begin{array}{c}t[R n] \\
\min \end{array}$ & $\begin{array}{l}t\left[H_{0}\right] \\
\min \end{array}$ & $\begin{array}{l}t\left[H_{9}\right] \\
\min \end{array}$ & $t\left[\underset{\min }{\left.(\partial \Theta / \partial z)_{9}\right]}\right.$ & $\begin{array}{c}U_{10} \\
\mathrm{~m} \cdot \mathrm{s}^{-1}\end{array}$ \\
\hline $\begin{array}{l}\text { moderate } \\
\text { wind }\end{array}$ & $05: 08 \sim 05: 45$ & $45 \pm 9$ & $84 \pm 29$ & $96 \pm 40$ & $124 \pm 48$ & $3.4 \sim 13.8$ \\
\hline weak wind & $05: 09 \sim 05: 43$ & $43 \pm 5$ & $57 \pm 13$ & $73 \pm 28$ & $95 \pm 25$ & $0.9 \sim 1.9$ \\
\hline (b) & sunset & $t[R n]$ & $t\left[H_{0}\right]$ & $t\left[H_{9}\right]$ & $t\left[-(\partial \Theta / \partial z)_{9}\right]$ & $U_{10}$ \\
\hline $\begin{array}{l}\text { moderate } \\
\text { wind }\end{array}$ & $17: 45 \sim 18: 05$ & $60 \pm 10$ & $103 \pm 11$ & $100 \pm 12$ & $109 \pm 21$ & $5.0 \sim 11.8$ \\
\hline
\end{tabular}




\subsection{Evening transition}

Fig. 11 shows an example of the time variation of physical quantities during the evening transitional processes. First the heat flux changes sign from plus to minus, 50 minutes later the net radiation changes sign. Containing other series, the average time intervals are shown in Table 2(b). In this case sunset time is the time origin. This transitional case consists of moderate wind data. The average evening transitions occur sequentially as follows ; $-(\partial \Theta / \partial z)_{9}=0, H_{9}=0$, $H_{0}=0, R n=0$ and $S^{\downarrow}=0$, but $H_{9}=0$ and $H_{0}$ $=0$ occur simultaneously. This transition is explained as follows. The heat flux from the surface becomes smaller and smaller with the decrease of sunshine, and the surface layer temperature begins to decrease. But at this time upward heat flux $H$ still exists. Thus C.G.H. continues for 9 minutes just after potential temperature gradient at $z=9 \mathrm{~m}$ becomes positive; after that time the heat flux $H_{9}$ becomes downward, and $\sigma_{\theta}(z=9 \mathrm{~m})$ becomes minimum. And 40 minutes later the net radiation becomes negative.

\subsection{Turbulent fluctuations}

Fig. 12 shows the non-dimensional turbulent fluctuations $\sigma_{w} / u_{*}$ versus non-dimensional stability length $\zeta$. Averaging time is 10 minutes. (a) gives the stable cases $(\zeta>0)$ and (b) the unstable cases $(\zeta<0)$. Open cir-

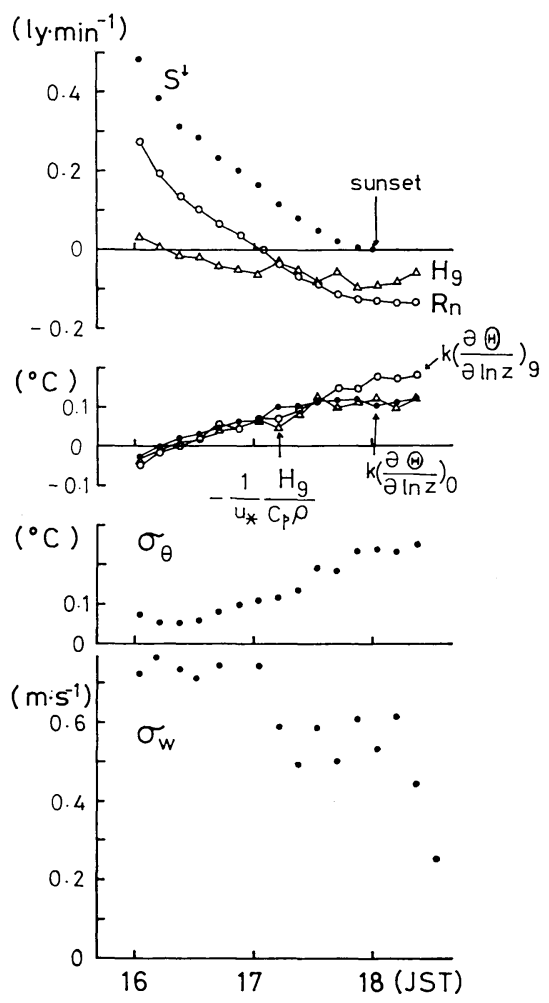

Fig. 11 Same as Fig. 10, but for evening transition.

cles indicate monotonic temperature profile data, closed circles indicate the existence of both stable and unstable profile data below $10 \mathrm{~m}$. From these figures, the results are (by eye)

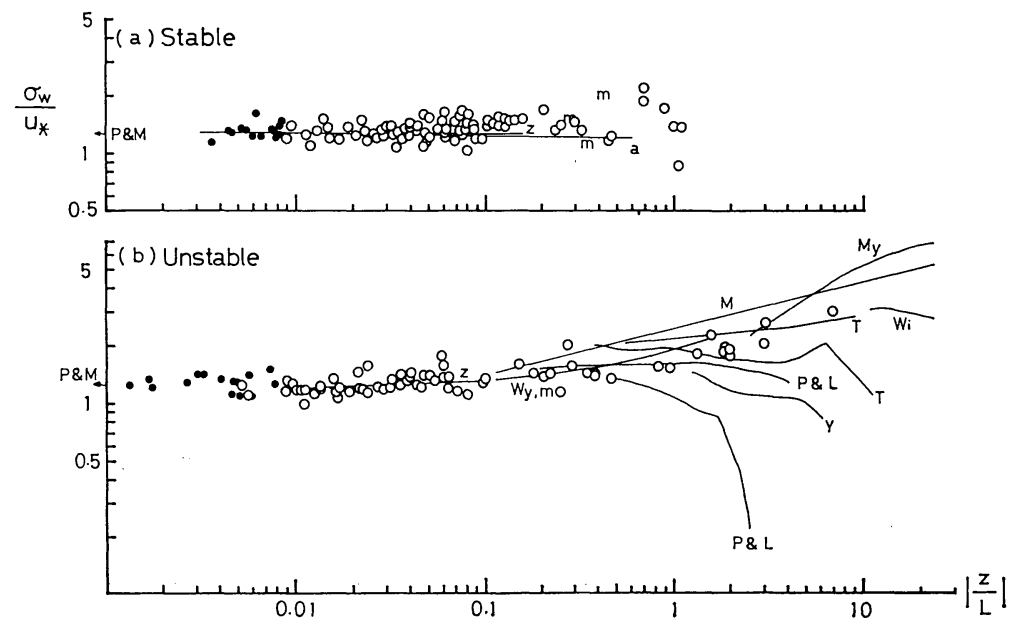

Fig. 12 Standard deviation of vertical wind velocity normalized by $u_{*}$ as a function of $\zeta$. (a) $\zeta>0$, (b) $\zeta<0$. 


$$
\frac{\sigma_{w}}{u_{*}}= \begin{cases}1.25-1.30 & -5 \times 10^{-2}<\zeta<1 \\ 1.6|\zeta|^{1 / 3} & -10<\zeta<-5 \times 10^{-2} .\end{cases}
$$

For references, thin solid lines indicate other observational results collected by Kondo (1982b, page 125).

Fig. 13 shows the non-dimensional temperature fluctuation $\sigma_{\theta} / \theta_{*}$ versus $\zeta$. (a) gives the stable cases $(\zeta>0)$ and (b) the unstable cases $(\zeta<0)$. Plotting data are only for the "Monotonic profile" case. The "Stable above the unstable profile" case is discussed in the next section. From this figure one obtains,

$$
\frac{\sigma_{\theta}}{\theta_{*}}= \begin{cases}2.5-3.0 & 10^{-2}<\zeta<1, \zeta \sim-10^{-2} \\ |\zeta|^{-1 / 3} & -10<\zeta<-2 \times 10^{-2} .\end{cases}
$$

Thin solid lines indicate other observational results collected by Kondo (1982b, page 126). Stability dependence of turbulent fluctuations in transitional state has the same tendency in steady state.

\subsection{Temperature fluctuations around neutral condition}

Under near-neutral conditions, the value of $\theta_{*}$ is zero but that of $\sigma_{\theta}$ is a finite minimal value $\sigma_{\theta, \mathrm{min}}$. Fig. 14 indicates the relation between $\sigma_{\theta}$ and $\theta_{*}$. The plotted points are classified according to the magnitude of $|\zeta|$.
The following results are obtained by inspection

$$
\begin{gathered}
\sigma_{\theta}=2.7\left|\theta_{*}\right|, \quad \text { for }\left|\theta_{*}\right|>0.02^{\circ} \mathrm{C} \\
\sigma_{\theta, \min }=\left\{\begin{aligned}
& 0.08, \text { for }\left|\theta_{*}\right|<0.02^{\circ} \mathrm{C} \\
& \text { Monotonic profile) } \\
& 0.06, \text { for }\left|\theta_{*}\right|<0.02^{\circ} \mathrm{C} \\
& \text { Stable above the } \\
&\text { unstable profile })
\end{aligned}\right.
\end{gathered}
$$

Eq. (24) agrees with Eq. (23). The solid line and dotted curve show Eq. (25) and Eq. (26), respectively. The reason why the value of $\sigma_{\theta, \min }$ for "Stable above the unstable profile" is smaller than that for "Monotonic profile" is explained as follows; the former has a near-neutral temperature gradient within the middle part of the layer. These results are the case of 10 minutes averaging time. If 1 minute averaging times were used, $\sigma_{\theta, \min }$ would be about one half of the above value.

\section{$3.9 \theta_{*}$ in nocturnal quasi-steady state}

In the previous sections, mainly transitional cases are analyzed. In this section, quasisteady states during the night are dealt with.

For very stable condition, the velocity profile is nearly linear, so that the relation between the wind velocity of higher level and surface friction velocity is as follows: (Kondo, 1982a, see Appendix)

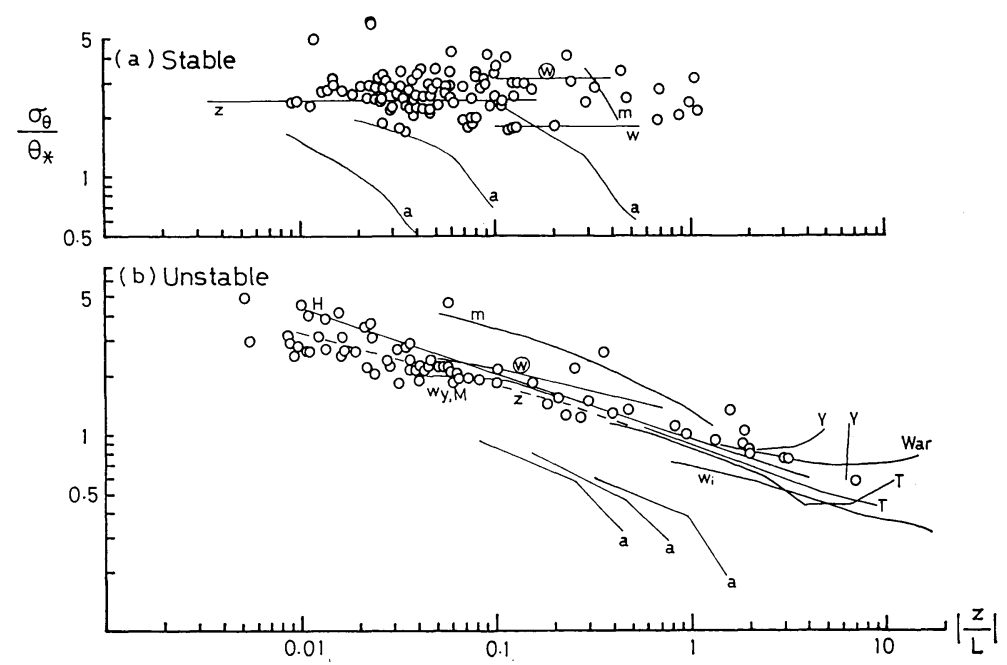

Fig. 13 Standard deviation of temperature normalized by $\theta_{*}$ as a function of $\zeta$. (a) $\zeta>0$, (b) $\zeta<0$. 


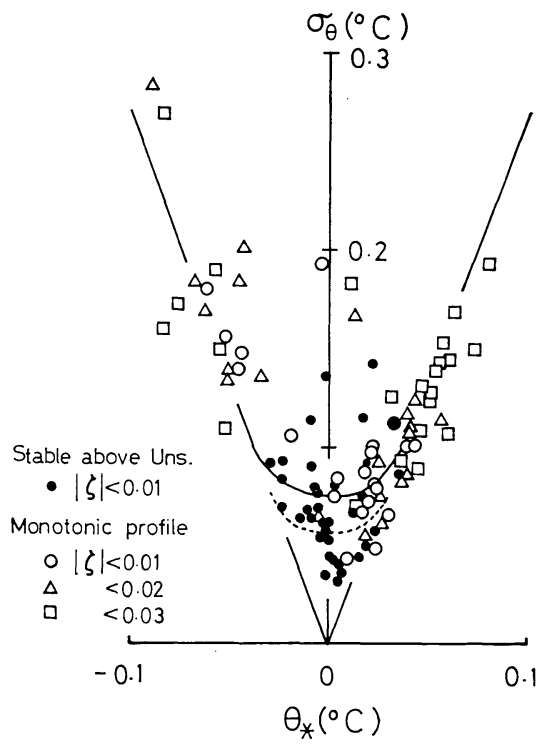

Fig. 14 Relation between $\sigma_{\theta}$ and $\theta_{*}$. Data are divided according to $|\zeta|$.

$$
u_{*}^{2}=K_{M} \frac{d U}{d z} \sim K_{M} \frac{U_{h}}{h}
$$

where

$$
K_{M}=\frac{k u_{*} z}{\varphi}
$$

and $h$ is the top of the boundary layer during night. According to the findings of Kondo et al. (1978) the non-dimensional shear function for very stable conditions becomes

$$
\varphi=1+7 \frac{z}{L} \sim 7 \frac{z}{L}-, \quad \text { for } \quad 0.01 \leqq \frac{z}{L} \leqq \frac{5}{7} .
$$

The relation between the cooling of the atmosphere and the surface heat flux is approximately,

$$
u_{*} \theta_{*} \doteqdot \frac{1}{2}\left|\left(\frac{\partial \Theta}{\partial t}\right)_{0}\right| h \doteqdot \frac{1}{2}\left|\left(\frac{\partial \Theta}{\partial t}\right)_{z}\right| h
$$

Where $(\partial \Theta / \partial t)_{0}$ is the surface cooling rate, $(\partial \Theta / \partial t)_{z}$ is the cooling rate at $z(\leqq 2 \mathrm{~m})$. From Eq. (27) to (30), one obtains

$$
\theta_{*}=\sqrt{U_{h}\left|\left(\frac{\partial \Theta}{\partial t}\right)_{z}\right|\left\{2 \times 7 \cdot \frac{g}{\Theta}\right\}^{-1}}
$$

The values of $\theta_{*}$ can be calculated from $U_{h}$

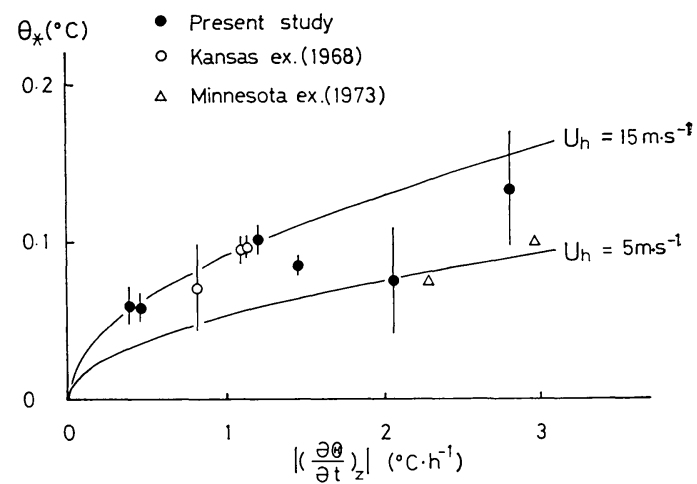

Fig. 15 Scaling temperature $\theta_{*}$ versus surface cooling rate in nocturnal quasi-steady state. Data are averages over a night. The curves are calculated by Eq. (31) for $U_{h}=5 \mathrm{~m} \cdot \mathrm{s}^{-1}$ and $U_{h}=15 \mathrm{~m} \cdot \mathrm{s}^{-1}$.

and surface cooling rate. Two lines calculated from Eq. (31) for $U_{h}=5 \mathrm{~m} \cdot \mathrm{s}^{-1}$ and $U_{h}$ $=15 \mathrm{~m} \cdot \mathrm{s}^{-1}$ are indicated in Fig. 15. Plotting data in the figure show the observational results averaged over a night for quasi-steady state. The data of the Kansas experiment of 1968 (Izumi, 1971) and Minnesota experiment of 1973 (Izumi \& Caughey, 1976) are also plotted in the figure. The observational values are bounded by the two theoretical curve.

The temperature cooling rate is normally about $1^{\circ} \mathrm{C} \cdot \mathrm{hr}^{-1}$ during an ordinary clear night and the wind speed near the top of atmospheric boundary layer is around $10 \mathrm{~m} \cdot \mathrm{s}^{-1}$, so that $\theta_{*}$ has a constant value $0.06-0.1^{\circ} \mathrm{C}$. The above theory supports the observational findings of Venkatram (1980) that $\theta_{*}=0.08^{\circ} \mathrm{C}$.

\subsection{0 $\mathrm{H} / \mathrm{Rn}$ in nocturnal quasi-steady state}

The net radiation flux is usually constant in steady stable conditions at clear night. The present observations indicate

$$
R n \doteqdot-0.09 l y \min ^{-1}\left(=62.8 \mathrm{~W} \mathrm{~m}^{-2}\right)
$$

This may be the normal value in clear nights almost all over the glove except for the polar regions. On the basis of these results, one would expect

$$
\frac{H}{R n}=-\frac{C_{p} \rho u_{*} \theta_{*}}{R n}=B u_{*}
$$




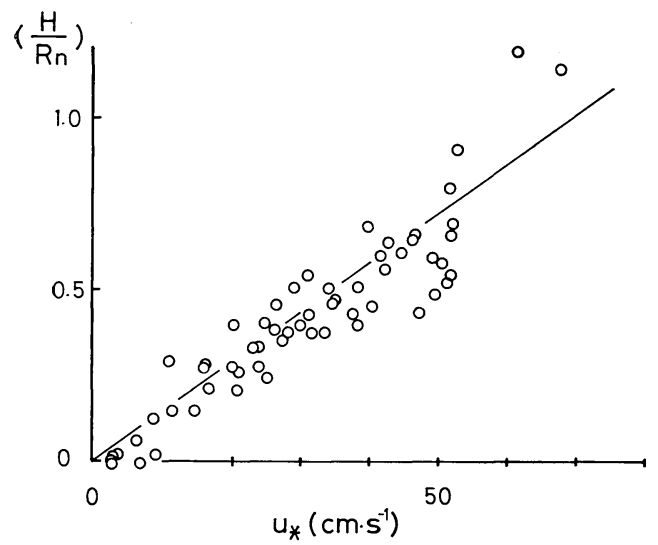

Fig. 16 The ratio of heat flux to net radiation $(H / R n)$ versus friction velocity $\left(u_{*}\right)$ in the nocturnal quasi-steady state.

$$
B=-\frac{C_{p} \rho \theta_{*}}{R n}=0.014 \mathrm{~s} \cdot \mathrm{m}^{-1}
$$

The solid line in Fig. 16 is the relation given by Eq. (32). The data were obtained at night during our experiments.

\section{Conclusions}

A set of data resulting from observations in the surface boundary layer is analyzed. The results may be summarized as follows.

(1) The heating rate of the surface layer agrees with that calculated by the flux divergence. On average, the change in temperature by horizontal advection is small. This observational site may be considered horizontally homogeneous terrain.

(2) There are two different types of breakup processes of the surface inversion layer, depending on the mean wind velocity. In the calm wind case $\left(u_{*}<10 \mathrm{~cm} \cdot \mathrm{s}^{-1}\right.$ or $U_{10}<2 \mathrm{~m}$ $\left.\cdot \mathrm{s}^{-1}\right)$, a strongly unstable layer is developed near the surface about one hour after sunrise. The stable layer on top is eroded by hot bubbles from below. In the moderate wind case $\left(u_{*} \geqq 10 \mathrm{~cm} \cdot \mathrm{s}^{-1}\right.$ or $\left.U_{10} \geqq 2 \mathrm{~m} \cdot \mathrm{s}^{-1}\right)$, the whole surface layer $(z \leqq 10 \mathrm{~m})$ is heated equally while remaining a stable layer. This condition is continued for 1-3 hours after sunrise.

(3) A counter gradient heat flux (C. G. H.) was observed under near neutral conditions $(0<R i<0.02)$. Two C.G.H. mechanisms are proposed. One is an exchange process be- tween neighboring hot and cold bubbles, the other is the penetration of hot bubbles into the stable layer.

(4) The first of these two mechanisms is used for estimating the mixing length $\left(l_{0}\right)$ at the height where $\overline{\theta w}=0$. This consideration is also applied in the mixed layer, for which values of $l_{0}=15-47 \mathrm{~m}$ are obtained.

(5) In the transitional stage, the flux Richardson number is zero, when $R i=0.003$ for the "Monotonic profile" cases, and $R i=$ 0.02 for the "Stable above the unstable profile" cases. For both cases, the following relation was obtained.

$$
\begin{aligned}
& \overline{\theta w}>0 \text { for }\left(\frac{\partial \Theta}{\partial z}\right)<0.005^{\circ} \mathrm{C} \cdot \mathrm{m}^{-1} \\
& \overline{\theta w}=0 \text { for }\left(\frac{\partial \Theta}{\partial z}\right)=0.005^{\circ} \mathrm{C} \cdot \mathrm{m}^{-1} \\
& \overline{\theta w}<0 \text { for }\left(\frac{\partial \Theta}{\partial z}\right)>0.005^{\circ} \mathrm{C} \cdot \mathrm{m}^{-1} .
\end{aligned}
$$

(6) Values of $\alpha(\zeta)=K_{H} / K_{M}$ are larger than 1 under unstable condition and smaller than 1 in stable condition.

(7) The transitions during the morning hours after sunrise, occur sequentially in the following order; $R n=0, H_{0}=0, H_{9}=0$ and $(\partial \Theta / \partial z)_{9}=0$. The transitions of the evening come as follows; $(\partial \Theta / \partial z)_{9}=0, H_{9}=0, H_{0}=0$ and $R n=0$ in the order, but $H_{9}=0$ and $H_{0}=0$ occur simultaneously.

(8) The turbulent intensities $\sigma_{\theta} / \theta_{*}$ and $\sigma_{w} / u_{*}$ are nearly constant under stable conditions. For unstable conditions, the following relation is obtained,

$$
\frac{\sigma_{\theta}}{\theta_{*}} \propto|\zeta|^{-1 / 3}, \quad \frac{\sigma_{w}}{u_{*}} \propto|\zeta|^{1 / 3} .
$$

(9) Under near neutral conditions, the temperature variance $\sigma_{\theta}$ is $2.7\left|\theta_{*}\right|$ for $\left|\theta_{*}\right|$ $>0.02^{\circ} \mathrm{C}$, but $\sigma_{\theta}$ has a minimum value $\sigma_{\theta}$, min $=0.08^{\circ} \mathrm{C}$ ("Monotonic profile" cases), $\sigma_{\theta, \min }$ $=0.06^{\circ} \mathrm{C}$ ("Stable above the unstable profile" cases) for $\left|\theta_{*}\right|<0.02^{\circ} \mathrm{C}$.

(10) The scaling temperature $\theta_{*}$ is calculated approximately for nocturnal steady stable conditions by using the higher level wind velocity $U_{h}$ and the cooling rate in the surface layer $(\partial \Theta / \partial t)_{z}$. The average value of $\theta_{*}$ is 
of the order of $0.06^{\circ} \mathrm{C}-0.1^{\circ} \mathrm{C}$.

(11) For steady, stable clear night time conditions, the following empirical relation was obtained; $H / R n=B u_{*}$ where $B=0.014$ $\mathrm{s} \cdot \mathrm{cm}^{-1}$ is a constant.

\section{Acknowledgements}

The authors thank Professor Wilfried Brutsaert of Cornell University for many helpful comments on the manuscript during his stay at Tohoku University. The authors are also grateful to the family of $\mathrm{Mr}$. R. Kimura for their helpful service and permission to use the rice paddies and to Institute of Coastal Oceanology for permitting the use of the computer facilities.

\section{Appendix}

Summary of Kondo's stable layer model (1982a)

In a stable boundary layer formed by surface air cooling, the wind profile is approximately logarithmic near the surface and linear above it. This is what is commonly called the "log-linear profile". Higher up, where the shear stress becomes very small it may be assumed that the wind speed approaches the free wind speed $U_{h}$. Fig. A(a) indicates the wind profile for this model boundary layer. In general, the shear stress may be taken to be the product of the diffusivity and the vertical gradient of wind speed. The surface shear stress $(-\rho \overline{u w})$ is thus approximately expressed by Eq. (27).

Next let's consider temperature cooling. In general, the night time downward heat flux is maximal at the surface and it decreases with height. It approaches zero at the top of the boundary layer. Also the vertical gradient of this heat flux : $|\partial H / \partial z|$ is maximal at the surface and it becomes smaller with height. As the cooling rate of the air is proportional to the heat flux divergence $(\partial \Theta / \partial t \propto \partial H / \partial z)$, the rate of decreases of the temperature is maximal at the surface and smaller with height. This is illustrated by the dot-dash line in Fig. A(b). The total atmospheric cooling especially at night is caused not only by heat flux divergence and but also by the radiational flux divergence. The latter, usually, exists from the surface

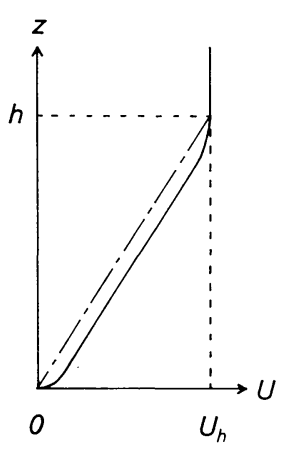

(a)

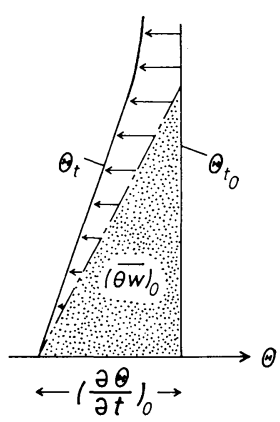

(b)
Fig. A Nocturnal stable state. (a) Modeling of wind profile, $h$ is the height of the boundary layer. (b) Time variation of the temperature profile. The dotted part is equal to the temperature flux at the surface $(\overline{\theta w})_{0}$. The arrows indicate the cooling by atmospheric radiation. Immediately near the actual surface there exists a complicated distribution of cooling rates resulting from the effects of radiation and turbulence (in this part molecular thermal conductivity must also be included). This complicated distribution does not exert an important influence on the overall cooling of the surface layer, so that it is omitted for simplicity.

to a height of about handred meters which is higher than the height where the turbulent heat flux divergence becomes negligible. This modeling is shown in Fig. A(b) (see also Kondo et al , 1978). Note that the more complicated structure of cooling mechanisms very close to the surface is omitted in this figure.

In the figure, the arrows indicate the cooling by divergence of atmospheric radiation; the dotted part is the cooling by turbulent heat flux divergence. As can be seen in this figure, the temperature flux at the surface $(\overline{\theta w})_{0}$ is approximately equal to the area of the triangle, so that it can be formulated by Eq. (30).

\section{References}

Bunker, A.F., 1956: Measurements of countergradient heat flows in the atmosphere. Austral. J. Phys., 9, 133-143.

Businger, J. A., J. C. Wyngaard, Y. Izumi and E. F. Bradley, 1971: Flux-profile relationships in the atmospheric surface layer. J. Atmos. Sci., 28, 181-189.

Caughey, S. J., J. C. Wyngaard and J. C. Kaimal, 1979: Turbulence in evolving stable boundary layer. J. Atmos. Sci., 36, 1041-1052. 
Clarke, R. H., A. J. Dyer, R. R. Brook, D. G. Reid and A. J. Troup, 1971: The Wangara Experiment. Boundary Layer Data, Div. of Meteor. Phys., Tech. paper, No. 19, CSIRO, Austral. and R. R. Brook, 1979: The Koorin expedition. Department of Sci. and Environm. Bureau Meteor. Austral.

Deardorff, J. W., 1966: The counter-gradient heat flux in the lower atmosphere and in the laboratory. J. Atmos. Sci., 23, 503-506.

—, 1967 : Empirical dependence of the eddy coefficient for heat upon stability above the lowest $50 \mathrm{~m}$. J. Appl. Meteor., 6, 631-643.

Izumi, Y., 1971: Kansas 1968 Field Program Data Report. U.S. Air Force Cambridge Res. Lab. Environm. Res. Pap., No. 379, (AFCRL-72-0041). and J. S. Caughey, 1976: Minnesota 1973 Atmospheric Boundary Layer Experiment Data Report. U.S. Air Force Cambridge Res. Lab. Environm. Res. Pap., No. 547, (AFCRL-76-0038).

Kaimal, J. C., J. C. Wyngaard, D. A. Haugen, O. R. Cote, Y. Izumi, S. J. Caughey and C. J. Readings, 1976: Turbulence structure in the convective boundary layer. J. Atmos. Sci., 33, 2152-2169.

Kondo, J., O. Kanechika and N. Yasuda, 1978: Heat and momentum transfers under strong stability in the atmospheric surface layer. J. Atmos. Sci., 35, 1012-1021.

, 1981: Analysis on the atmospheric- and oceanic-mixed layers. Marine Sciences, 13, 391397. (in Japanese)

- 1982a: Preliminary theoretical study on nocturnal cooling over complex terrain. Tenki, 29, 935-949. (in Japanese)

- 1982b: Science of Atmospheric Boundary Layer. Tokyodo Press, pp. 219. (in Japanese) and T. Sato, 1982: The determination of the von Kármán constant. J. Meteor. Soc. Japan, 60, 461-471.
Mitsuta, Y. and O. Tsukamoto (ed.), 1975: AMTEX data Report, Vol. 8 (Aircraft observations), Management Committee for AMTEX.

Muller, J. G. and H. Hinzpeter, 1974: Measurements of the turbulent heat flux over the sea. Boundary Layer Meteor., 6, 47-52.

Naito, G., 1977 : Direct measurements of momentum and sensible heat transfers in the atmospheric boundary layer near the sea surface. Rep. Nat. Res. Center Disaster Prevention, No. 17, 189-213. (in Japanese)

Pond, S., G. T. Phelps and J. E. Paquin, 1971: Measurements of the turbulent fluxes of momentum, moisture and sensible heat over the ocean. $J$. Atmos. Sci., 28, 901-917.

Telford, J. W. and J. Warner, 1964: Flux of heat and vapor in the lower atmosphere derived from aircraft observations. J. Atmos. Sci., 21, 539-548.

- 1966: The convective mechanism in clear air. J. Atmos. Sci., 23, 652-666.

Venkatram, A., 1980 : Estimating the Monin-Obukhov length in the stable boundary layer for dispersion calculations. Boundary Layer Meteor., 19, 481-485.

Webb, E. K., 1958: Vanishing potential temperature gradients in strong convection. Quart. J. R. Met. Soc., 84, 118-125.

Wieringa, J., 1980: A revaluation of the Kansas mast influence on measurements of stress and cup anemometer overspeeding. Boundary Layer Meteor., 18, 411-430.

Wong, E. Y. J. and K. C. Brundidge, 1966: Vertical and temporal distributions of the heat conductivity and flux. J. Atmos. Sci., 23, 167-178.

Yaglom, A. M., 1977 : Comments on wind and temperature flux-profile relationship. Boundary Layer Meteor., 11, 89-102.

Yamamoto, G., 1952: On a radiation chart. Sci. Rep. Tohoku Univ. Ser. 5, 5, 9-23.

\title{
接地気層の朝・タの遷移過程の研究
}

\author{
近藤 純 正・萩野谷 成 徳 \\ 東北大学理学部地球物理学教室
}

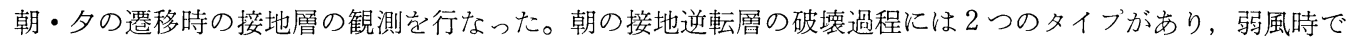
は，安定な接地層は地表面近くに不安定層が形成されることなく，汪ぼ一様な昇温率で加熱されるのに対し， 微風時には最初に地表面付近に不安定層が形成され，その後昇温過程が上層へ伝播していくことが分った。接 地逆転層遷移過程に拈いて，温位の低い方向とは逆の方向に顕熱が伝わる現象，いわゆる counter gradient

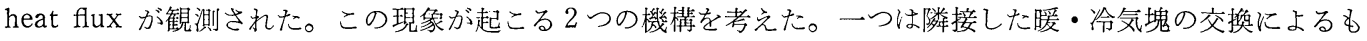
の，他は安定層中への暖気塊の貫入によるものである。この機構のモデルを用いて，遷移㭙における接地層内 の混合距離を求めた。さらにこのモデルを不安定な混合層上部の counter gradient heat flux が観測される 層へ応用し混合距離を求めたところ, 混合距離は約 $15 \sim 47 \mathrm{~m}$ であり, 混合距離と高度の比は 0.04 であるこ こが得られた。

準定常時の夜間においては，摩擦温度 $\theta_{*}$ は風速と地表の冷却率に依存し，多くの場合， $\theta_{*}$ は $0.06 \sim 0.1^{\circ} \mathrm{C}$ である。これは理論的にも説明された。顕熱と正味放射量の比は地表面摩擦速度に比例することも示した。 